\title{
Brazilian Immigrant Adolescents: Stress and Support Identified in Ecomap Drawings
}

\author{
Rachel Tennant ${ }^{1}$, Chieh $\mathrm{Li}^{1}$, Louis Kruger ${ }^{1} \&$ Soraia Leite ${ }^{2}$ \\ ${ }^{1}$ Department of Applied Psychology, Northeastern University, USA \\ ${ }^{2}$ Framingham Public Schools, USA \\ Correspondence: Rachel Tennant, Department of Applied Psychology, Northeastern University, 360 Huntington \\ Ave, Boston, MA 02115, USA. Tel: 267-253-4449. E-mail: rachel.ruah@ gmail.com
}

\author{
Received: October 4, 2018 Accepted: October 26, $2018 \quad$ Online Published: November 11, 2018 \\ doi:10.5539/hes.v8n4p139 URL: https://doi.org/10.5539/hes.v8n4p139
}

\begin{abstract}
This study investigated the perceived sources of support and stress of Brazilian immigrant adolescents living in the United States. The sample was comprised of 62 Brazilian immigrant adolescents between the ages of 14 and $19(M=16.55, S D=1.31)$. The study also explored how these individuals cope with stress and how they help their friends. Perceived sources of support and stress were assessed by Ecomap drawings and a questionnaire. Thematic and frequency analyses were conducted to identify major sources of support and stress for this group. Results revealed that the most frequently reported sources of support were exercise, sports, family members, and friends. A culture-specific source of support for the males of this group was soccer. The most commonly reported sources of stress were the difficulty and quantity of schoolwork and relationships with parents. Participants depicted ambivalent relationships in their lives through their Ecomap drawings. Family members, teachers, learning English, and jobs were perceived as sources of both support and stress. Each student's cluster of support and stressors was also reflected in their Ecomap drawings. Participants described listening to music, spending time alone, and exercising as strategies for coping with stress. Participants help their friends to cope with distress by consoling, spending time together, and providing social support. Results from this study were distinct from those of similar studies with other populations such as immigrants from another country or Brazilians in Brazil. Implications of these findings for culturally sensitive education and student services in higher education were discussed.
\end{abstract}

Keywords: Brazilian immigrant adolescents, support, stress, Ecomap, ecological perspective, coping

\section{Introduction}

Although 336,000 Brazilian immigrants are living in the United States, little is known regarding their experiences (Zong \& Batalova, 2016). Although researchers have studied the experiences of Brazilian adults and families living in the United States (Joseph, 2011; Margolis, 2013), few have focused specifically on Brazilian adolescents. The current study aims to address this need by investigating the stress and support among Brazilian adolescents living in the United States. This information may assist educators, psychologists, counselors, mental health providers, and parents in their efforts to provide culturally sensitive education and support to this population in the U.S., Canada, and other countries that have Brazilian immigrants.

Racial and ethnic categories commonly recognized in the United States are inappropriate for Brazilian individuals, making it difficult to estimate the number of Brazilians living in the United States (Margolis, 2013). For example, the U.S. census does not provide Brazilians with the opportunity to select "Brazilian" as their ethnicity (Zubaran, 2008). The number of undocumented Brazilian immigrants living in the United States contributes to the fear and anxiety experienced by this population (Joseph, 2011) and is another barrier to research with this group. Zong and Batalova (2016) estimated that one-third to one-fifth of the Brazilian immigrants in the United States are undocumented.

For many Brazilians, migration to the United States is viewed as an accomplishment and an avenue to achieving a better quality of life (Joseph, 2011; Margolis, 2013). It is also viewed as an opportunity to help those living in their home country by sending money to their family members (Joseph, 2011), or an opportunity to save money so that they can return to Brazil and build a house (Margolis, 2013). Despite these positive prospects, Brazilians, 
similar to other South-American immigrants, also face difficulties when they migrate to the United States, such as a lack of English language proficiency, documentation status, and acculturative stress (Margolis, 2013). These challenges have been shown to negatively influence immigrant mental health (Joseph, 2011).

Bronfenbrenner's (1979) ecological model is useful in understanding the sources of stress and support experienced by immigrants in various settings (e.g., school, home) and the interconnections between these environments. According to Nastasi and Borja (2016), these multiple ecological systems are crucial for understanding children and adolescents' overall development and their psychological well-being. Braga (2012), for example, took an ecological approach to studying Brazilian adolescents in Massachusetts. Braga focused on this population's microsystem, including family, school, and religious institutions. Most Brazilian immigrant adolescents reported feeling close to their families, being affiliated to a specific religion, and many shared an appreciation of teachers.

Based on Bronfenbrenner's ecological model, the Ecomap was developed as a qualitative assessment that provides a visual display of various aspects of an individual's environment and how they are interconnected (McCormick, Stricklin, Nowak, \& Rous, 2008). Ecomaps have been used in nursing, psychology, and social work research to gather information regarding the sources of support and stress in a person's life through a simple drawing (Nastasi \& Borja, 2016; Lizardi \& Carregari, 2016; Li \& Li, 2016; Driessnack, 2005). These drawings also provide information about possible ambivalent relationships in one's life. For the purposes of this study, an ambivalent relationship is a relationship that is perceived to be both a source of support and stress. More recently, Nastasi, Borja, and Summerville (2017) described the use of the ecomap as a mixed methods research tool to understand children's views about what supports and stressors are present in their lives. In addition, the ecomap has been used as an open-ended qualitative tool in a variety of countries, including Australia, Canada, Greece, Brazil, the United States, and more (Borja, Nastasi, \& Sarkar, 2017). It has also been used with individuals who have varying cognitive and developmental abilities (Hodge \& Limb, 2011).

In addition to the ecological model, this study also views adolescents from a developmental perspective, which emphasizes age-specific supports and stressors that are crucial in developmental growth (Cicognani, 2011). During adolescence, individuals may experience stressors related to relationships (e.g., parents, peers) and school (e.g., homework). For example, Cicognani (2011) describes the importance of supportive family and peer relationships at this age because they can help adolescents cope with these age-normative challenges.

Lizardi and Carregari (2016) used the ecomap to identify the sources of stress and support of six to 17-year-old Brazilians living in Brazil. Common stressors for these participants were death of a loved one, being verbally or physically hurt by someone, school difficulties (e.g., getting poor grades, being retained in grade level, too much homework) and violence in their communities. In addition, female adolescents reported that taking care of a sibling was a stressor. Multiple relationships, including those with parents, teachers, and friends, were also identified as being supportive. Although certain stressors may be specific to Brazil or the Brazilian city where the study was conducted, Brazilian adolescents living in the United States may also experience some of these same stressors. Furthermore, Brazilian adolescents living abroad may have additional stressors related to their experiences as immigrants as has been shown in studies investigating the stressors associated with immigration of Brazilian adults (Joseph, 2011; Margolis, 2013).

$\mathrm{Li}$ and $\mathrm{Li}$ (2016) used Ecomap drawings in conjunction with focus groups to study the psychological wellbeing of 10 to 17-year-old Chinese immigrant adolescents. These authors found that high expectations of academic performance, health-related difficulties (i.e., lack of sleep and feeling sick), managing teacher and parent expectations, friendship challenges, and instability at home were important contributors to these adolescents' stress. $\mathrm{Li}$ and $\mathrm{Li}$ also reported that family members, classmates/peers, and school staff (e.g., guidance counselors, teachers), were sources of support for these adolescents. Furthermore, parents, teachers, friends, siblings, and other relatives were identified as being both a source of stress and support. Activities such as shopping, traveling, and sports were also viewed as sources of both stress and support. School was the most ambivalent location. Although this population is culturally different from Brazilian adolescents, they nonetheless may share commonalities based on their experiences as immigrants.

Although little research has been conducted with Brazilian immigrant adolescents, studies have explored the experiences of Brazilian adolescents living in their native country (Mesquita \& Reimao, 2010; Morato, Giglio, \& Gomes, 2011). For example, Brazilian adolescents who have both family problems and low levels of social support from peers have been shown to be at a higher risk of depression (Zinn-Souza et al., 2008). Research has also identified specific supports for Brazilian immigrants such as churches (Margolis 2013). Churches provide social support through meetings, celebrations, and sports events. In addition, individuals can get information 
about housing, jobs, and other useful materials through churches (Margolis, 2013).

Although the role of soccer in the lives of Brazilian adolescents has not been systematically investigated, the media (Morato et al., 2011) portray soccer as being very important to Brazilians in their native country. Morato et al. (2011) argue that Brazilians idolize soccer players, and Brazilian children often want to become professional soccer players. Soccer may provide an opportunity for Brazilians to exercise and socialize with others while watching soccer matches. These cultural influences may also shape the professional aspirations of many young male Brazilian adolescents and may reduce stress in young Brazilian males even when they immigrate abroad.

Understanding the supports that a person experiences in life is important when considering how they will respond to stressful events. Because culture may impact how people cope with adverse situations (Wiese, 2010), it is particularly important to gain a better understanding of what a specific ethnic group of immigrants find supportive. Resilience has been defined as the process of adapting in the face of adversity (Newman, 2005). Research on resilience indicates that the connection and closeness that people feel to their family, peers, adults outside the family, school, and other places in their communities can help them cope with adversity (Resnick, 2000). As discussed by Masten (2003), schools are important in the development of resilience in children and adolescents, by providing opportunities for success. These sources of support can increase their resilience when they are exposed to risk factors related to being immigrants in a new country (Burgos, Al-Adeimi, \& Brown, 2016). A supportive family, for example, has been shown to be a source of resilience for immigrant youth and their parents, especially during times when youth are discriminated against based on their ethnic background (Burgos et al., 2016).

In summary, non-immigrant Brazilian children and adolescents experience various stressors in their lives, including violence in their communities, school difficulties, and death of loved ones (Lizardi \& Carregari, 2016). They also perceive themselves to have supportive relationships with parents, teachers, and friends. Soccer seems to have an important role in the goals and activities of Brazilian youth (Morato et al., 2011). Research on Chinese immigrant children and adolescents living in the United States suggest that academic pressure, competitions and artistic performance can be sources of stress ( $\mathrm{Li} \& \mathrm{Li}, 2016)$. In addition, sports and relationships with friends, teachers, and families were found to be sources of both stress and support (i.e., ambivalent relationships). However, it is unknown to what extent the research from other immigrant populations can be generalized to adolescent Brazilians. Individual differences in the experiences of Brazilian adolescents living in the U.S. have also not been the focus of research. The current study aims to address this gap in the research. The following research questions were developed with the mental health professionals at the study site to help inform them of how to better meet the mental health needs of Brazilian adolescents attending their high school in a multicultural community.

1. What are the perceived sources of support, stress, and ambivalence (both stress and support) for this population?

2. How do Brazilian adolescents cope with stress?

A comparison of the results of this study with previous studies may help illuminate the extent to which the sources of support and stress of Brazilian adolescent immigrants compare to those of other immigrant groups. This knowledge may help improve cultural sensitivity of services for this group of immigrant students in secondary and higher education.

\section{Method}

\subsection{Participants}

Participants were recruited from an urban high school in Massachusetts. Participants had at least one parent, who was born in Brazil. Parent or legal guardian consent was required for participants under the age of 18. Verbal assent was also provided by participants who were under the age of 18 prior to data collection. Sixty-two adolescents between the ages of 14 and $19(M=16.55, S D=1.31)$ participated in this study. The sample was comprised of $56 \%$ male and $44 \%$ female participants. There were $33.87 \%$ from the $9^{\text {th }}$ grade, $20.97 \%$ from the $10^{\text {th }}$ grade, $22.58 \%$ from the $11^{\text {th }}$ grade, and $22.58 \%$ from $12^{\text {th }}$ grade. They reported living in the United States between 2 months and 19 years $(\mathrm{M}=6.75, \mathrm{SD}=6.55)$. A majority of the participants $(91.94 \%)$ reported a preference for speaking Portuguese at home. The median annual household income of the town was $\$ 68,881$ (U.S. Census Bureau, 2014). Demographic information regarding the languages spoken by participants, religious affiliation, and ethnicity is provided in Table 1 . 
Table 1. Selected Demographics of Participants

\begin{tabular}{|c|c|c|}
\hline Variable & & $n$ (\% of participants) \\
\hline \multicolumn{3}{|l|}{ Age } \\
\hline & 14 & $3(4.84)$ \\
\hline & 15 & $12(19.35)$ \\
\hline & 16 & 15 (24.19) \\
\hline & 17 & $16(25.81)$ \\
\hline & 18 & $12(19.35)$ \\
\hline & 19 & $4(6.45)$ \\
\hline \multicolumn{3}{|l|}{ Gender } \\
\hline & Male & $35(56.45)$ \\
\hline & Female & $27(43.55)$ \\
\hline \multicolumn{3}{|l|}{ Grade } \\
\hline & 9 & $21(33.87)$ \\
\hline & 10 & $13(20.97)$ \\
\hline & 11 & $14(22.58)$ \\
\hline & 12 & $14(22.58)$ \\
\hline \multicolumn{3}{|c|}{ Ethnicity } \\
\hline & Brazilian & 38 (61.29) \\
\hline & White & $10(16.13)$ \\
\hline & Pardo & $4(6.45)$ \\
\hline & Latino & $2(3.22)$ \\
\hline \multicolumn{3}{|c|}{ Languages Spoken } \\
\hline & English and Portuguese & $29(46.77)$ \\
\hline & Portuguese & $28(45.16)$ \\
\hline & English & $1(1.6)$ \\
\hline \multicolumn{3}{|c|}{ Place of Birth } \\
\hline & Brazil & $41(66.13)$ \\
\hline & United States of America & $17(27.42)$ \\
\hline \multicolumn{3}{|c|}{ Religious Affiliation } \\
\hline & Catholic & $28(45.16)$ \\
\hline & Christian & $18(29.03)$ \\
\hline & Evangelist & $6(9.68)$ \\
\hline
\end{tabular}

\subsection{Measures}

\subsubsection{Questionnaire}

A brief open-ended questionnaire was designed for this study to gather information regarding participants' demographics including gender, age, birth place, number of years living in the United States, languages spoken, and religion. In addition, open-ended questions about what coping strategies they use and how they would help a friend in distress were also included in the questionnaire.

\subsubsection{Ecomap}

Ecomap drawings (see Figure 1 for an example) were used as an assessment of the participants' perceived supports and stressors in their environments. Hartman (1995) developed ecomaps as a paper and pencil tool that could be used for assessment, planning, and intervention for children and adults. Since then, it has also been used as a data collection and intervention tool in a variety of international studies to compare the experiences of children and adolescents from different cultural backgrounds (Borja et al., 2017). Research on the criterion-related validity of the instrument has supported its use as a method for assessing children's perceived environmental sources of stress and support (Summerville, 2014). Specifically, Summerville (2014) demonstrated that when controlling for gender, both ecomap support and ecomap stress were statistically related $(p<.05)$ to the Interpersonal Relations scale of the Behavior Assessment System for Children, Second Edition's (BASC-2). These results indicated that children who reported having stress in relationships on the BASC-2, were also more likely to report a higher number of sources of stress and lower number of sources of support in their ecomaps. 

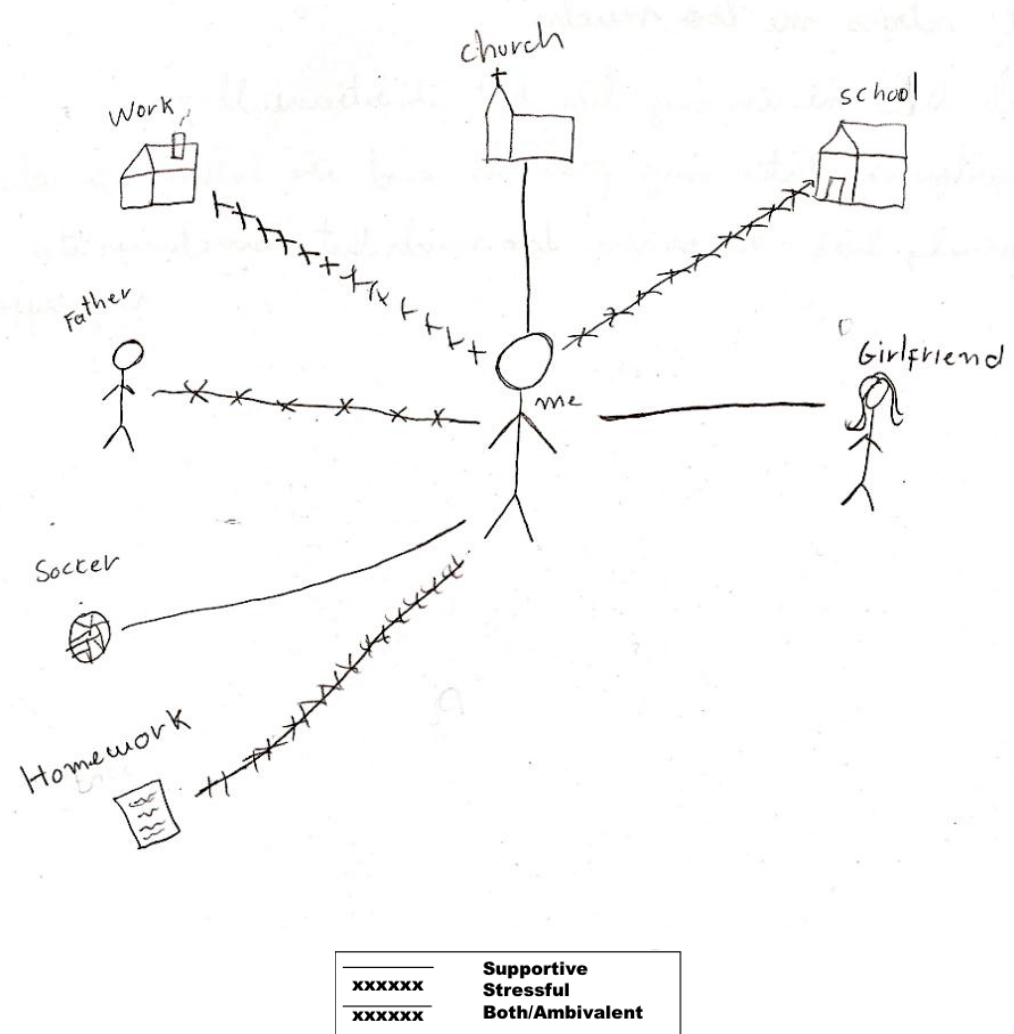

Figure 1. Example of Ecomap

The ecomap assessment seemed appropriate for this bilingual, immigrant group because it relies on a visual depiction of various aspects of an individual's environment, and therefore requires minimal English language proficiency to complete. In addition, the ecomap allows an individual to identify sources that are both stressful and supportive (i.e., reflective of ambivalence). According to Borja et al. (2017), it also facilitates a child's ability to think and communicate with adults using simple language, making it a developmentally appropriate tool for gathering data. Ecomap drawings provide an opportunity for individuals to describe and explore the relationships in their lives and the emotions that are experienced with each person, place, thing, or activity (Nastasi \& Borja, 2016).

\subsection{Procedure}

Participants completed the ecomap drawing and the questionnaire in a classroom after school. Most participants completed both tasks within 30 to 40 minutes. The bilingual school psychologist at the school and the researchers administered the open-ended questionnaire and Ecomap drawings (based on Nastasi and Borja's 2016 procedure). Participants were asked to visually describe the quality of their relationships by identifying each of these sources as stressful, supportive, or both (i.e., ambivalent) (Driessnack, 2005). They were taught to draw a solid line to represent a supportive relationship, a disconnected line using crosses to symbolize a stressful relationship, and a solid line with crosses to symbolize an ambivalent relationship that was perceived as being both stressful and supportive (see Figure 1).

The questionnaire was presented on a piece of paper, with a size of $8 \times 12$. The instructions were given in both English and Portuguese and participants were given the option to write in English, Portuguese, or a combination of both. Eighty-eight percent wrote their responses in English, 11\% in a combination of both English and Portuguese, and $1 \%$ in Portuguese.

\subsection{Data Analyses}

As recommended by Nastasi et al. (2017), the Ecomaps were analyzed qualitatively and then quantified to be presented as descriptive data. Network size was the sum of all relationships identified on the ecomap. The number of different (a) relationships, (b) sources of support, (c) sources of stress, and (d) ambivalent 
relationships were also calculated for each participant. The balance of stress and support (Stress-Support Index, SSI) was also calculated for each participant by coding each relationship numerically, with 1 for each source of support, 1.5 for each ambivalent source, and 2 for each stressful source. These numerical codes were then summed and divided by the total number of sources in their ecomap (Nastasi et al., 2017). Qualitative themes were then identified. Based on the responses provided by participants, the relationships represented in the ecomap were classified into the following categories: people, faith, places, activities, and things. In the example shown in Figure 1, the Ecomap would be coded as having three sources of support: a person (girlfriend), a place (church), and an activity (soccer). This individual also reported one place (work) as stressful. The ambivalent sources (sources of both support and stress) were a person (father), a place (school), and an activity (doing homework). All ecomaps were coded in this manner. The final Coding Framework is provided in Appendix A.

Responses to the questionnaire were entered into a data sheet. Demographic information (e.g., age, grade, etc.) was collected in written form and analyzed quantitatively. Answers to questions about how participants cope with stress and how they help their friends cope with stress were initially coded qualitatively. Themes were deducted by the researchers and then analyzed quantitatively into descriptive statistics.

\subsection{Data Trustworthiness}

The trustworthiness of the data is supported by three factors. First, three of the authors are bilingual and two of them are Portuguese-English speaking school psychologists who have work and non-work experiences interacting with Brazilian immigrant parents and children. All authors also have experience conducting research with immigrants. Second, bilingual Portuguese school psychologists, who had good rapport with the participants, administered the ecomap and the questionnaire. Third, the participants were allowed to use their preferred language (Portuguese, English, or a combination of both languages) to complete the ecomap and the questionnaire.

Based on criteria recommended by Nastasi and Schensul (2005), cross-validation was also used as an indicator of data trustworthiness. The first and second authors checked the accuracy of each data entry and quantitative analysis. These authors also checked the classification of responses with each other. Inconsistencies were resolved by discussing which category would be most applicable. A combination of deductive and inductive schemes was applied to analyze the data and create this coding framework. In addition, member checking, referring to the confirmation of the veracity of the data with a person of the population was used. Peer debriefing was also used to discuss data interpretation. Lastly, prolonged engagement was used to ensure that sufficient time was spent to understand the full scope of the topic.

\section{Results}

\subsection{Identified Sources of Support, Stress, and Ambivalent Relationships from Ecomaps}

Participants drew a mean of $7.93(S D=2.82)$ relationships in their ecomaps. The number of sources ranged from 3 to 17. Participants reported a mean of 3.69 sources of support $(S D=1.93), 2.23$ sources of stress $(S D=1.80)$, and 2.34sources of both stress and support $(S D=1.47)$. The Stress-Support Index was calculated for each participant and indicated that only one participant demonstrated only sources of support in her ecomap. Similarly, only one participants reported solely stressful relationships in his ecomap. The identified sources were categorized under the following themes: people (e.g., family members, school personnel, friends), faith (e.g., God), activities (e.g., exercise, work, learning English, homework), places (e.g., school church, gym), and things (e.g., money, pets) (see Table 2). With one notable exception pertaining to soccer, responses of male and female respondents were not notably different and therefore data are presented for the group rather than by gender.

\subsubsection{Activities}

Sixty-nine percent of participants mentioned a physical activity, such as going to the gym, exercising or playing sports, as a source of support. Fifty-seven percent of male participants (and none of the female respondents) identified soccer as a source of support. Schoolwork, such as homework, school projects, and specific subjects (e.g., mathematics), was described as stressful by $31 \%$ of participants. In addition, $13 \%$ of participants identified learning English as stressful.

\subsubsection{People}

Overall, family members and friends were frequently described as being either supportive or supportive and stressful. Specific family members were mentioned by $65 \%$ of participants as a source of support and by $50 \%$ of participants as a source of both support and stress (ambivalent). These family members included parents, aunts, uncles, siblings, cousins, and grandparents. Fifty-five percent of participants also identified specific friends as supportive. 


\subsubsection{Places}

Thirty-two percent of participants identified their church as a source of support in their ecomaps. Only 5\% of participants identified church as a place that was a source of both stress and support. Twenty-one percent of participants identified school as a source of both support and stress, $15 \%$ as a source of stress, and $13 \%$ as supportive. Thirty-four percent of participants included their workplace in their ecomaps, indicating that approximately one-third of participants reported having a job. Fifteen percent of participants identified their workplace as a source of both stress and support while $13 \%$ identified their job as a source of support, and $7 \%$ identified it as a source of stress.

\subsubsection{Things}

Twenty-three percent of participants identified money in their ecomaps. Sixteen percent of participants identified money as a source of stress.

Table 2. Frequently Identified Sources of Support, Stress, and Ambivalence in Ecomap

\begin{tabular}{llll}
\hline Theme & $\begin{array}{l}\text { Support } \\
n \text { (\% participants })\end{array}$ & $\begin{array}{l}\text { Stress } \\
n(\% \text { participants })\end{array}$ & $\begin{array}{l}\text { Support and Stress } \\
n \text { (\% participants) }\end{array}$ \\
\hline People & & & \\
$\quad$ Family Members & $38(65)$ & $16(26)$ & $31(50)$ \\
$\quad$ Friends & $34(55)$ & $2(3)$ & $11(18)$ \\
Places & & & \\
$\quad$ Church & $20(32)$ & - & $3(5)$ \\
$\quad$ School & $8(13)$ & $9(15)$ & $13(21)$ \\
$\quad$ Work & $8(13)$ & $4(7)$ & $9(15)$ \\
Activities & & & - \\
$\quad$ Playing Soccer & $20(32)$ & - & $1(2)$ \\
$\quad$ Exercise & $23(37)$ & - & $3(5)$ \\
$\quad$ Learning English & $1(2)$ & $8(13)$ & $7(11)$ \\
$\quad$ Schoolwork & - & $19(31)$ & - \\
Faith & & & - \\
$\quad$ God & $6(10)$ & - & \\
Things & & - & \\
$\quad$ Money & $1(2)$ & & \\
\hline
\end{tabular}

\subsection{How Do Participants Cope with Stress and Help Friends?}

Information about how Brazilian adolescent immigrants cope with stress and help their friends was gathered from the questionnaire. These responses were coded qualitatively by theme and then quantified to be presented as descriptive data. When asked about how they cope with stress, $26 \%$ of participants reported that they listen to music, $23 \%$ spend time alone (e.g., walk alone, go to room alone), $21 \%$ sleep, $15 \%$ exercise (e.g., go to gym, exercise, or played sports), $10 \%$ release their emotions (e.g. scream), and $8 \%$ process the situation by thinking about what happened. When asked how they would help a friend who was feeling upset, $98 \%$ of participants responded that they would console their friend by communicating with them (e.g., talk to them or giving them advice) and $60 \%$ reported they would spend time with the friend.

\subsection{Individual Differences}

Group results often obscure individual differences, and therefore it is important to understand the cluster of stressors and supports of an individual when designing interventions for the person. Participants A and B are good examples of the importance of understanding an individual's unique cluster of stressors and supports. Participant $\mathrm{A}$ is a 16-year old, $9^{\text {th }}$ grade student, who described a preference for speaking Portuguese at home and with friends. She was born in Brazil and had been living in the United States for 9 months at the time of the study. She identified only sources of support in her Ecomap. Figure 2 displays her ecomap, which shows only sources of support, indicating it is unlikely that she perceives much stress in her environment. She describes feeling supported by her friend, family, school, and her travel to Italy. In the questionnaire, she described having two friends and empathizing with them when they are upset. 


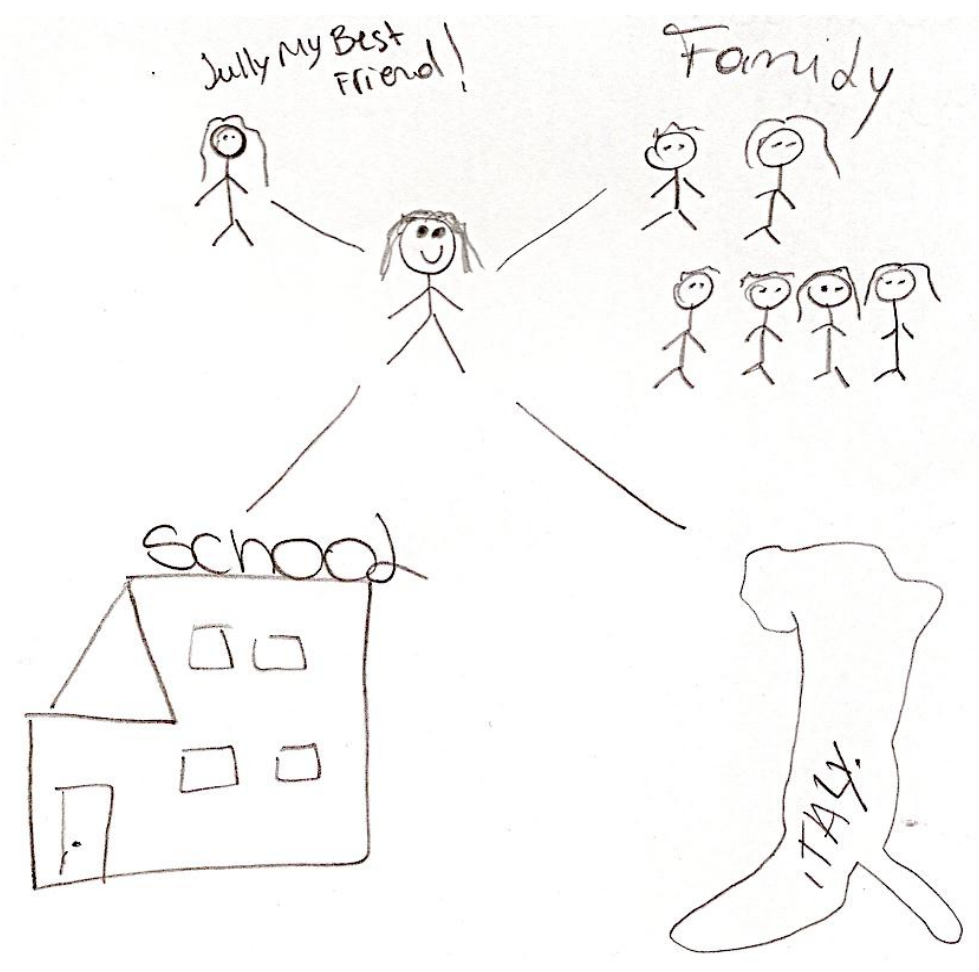

Figure 2. Example of Ecomap: Participant A

Participant B is a 19 -year-old, $11^{\text {th }}$ grade student. He also described a preference for speaking Portuguese at home and with friends. In his questionnaire, he described not having any friends in the United States. Unlike participant A, participant B's Ecomap displays more stressors, such as a lack of sleep, than supports in his life (see Figure 3). Participant B also identified interpersonal issues, such as the incivility of others, as a source of stress. Despite his interpersonal concerns, he expressed a desire to help friends when they are upset.

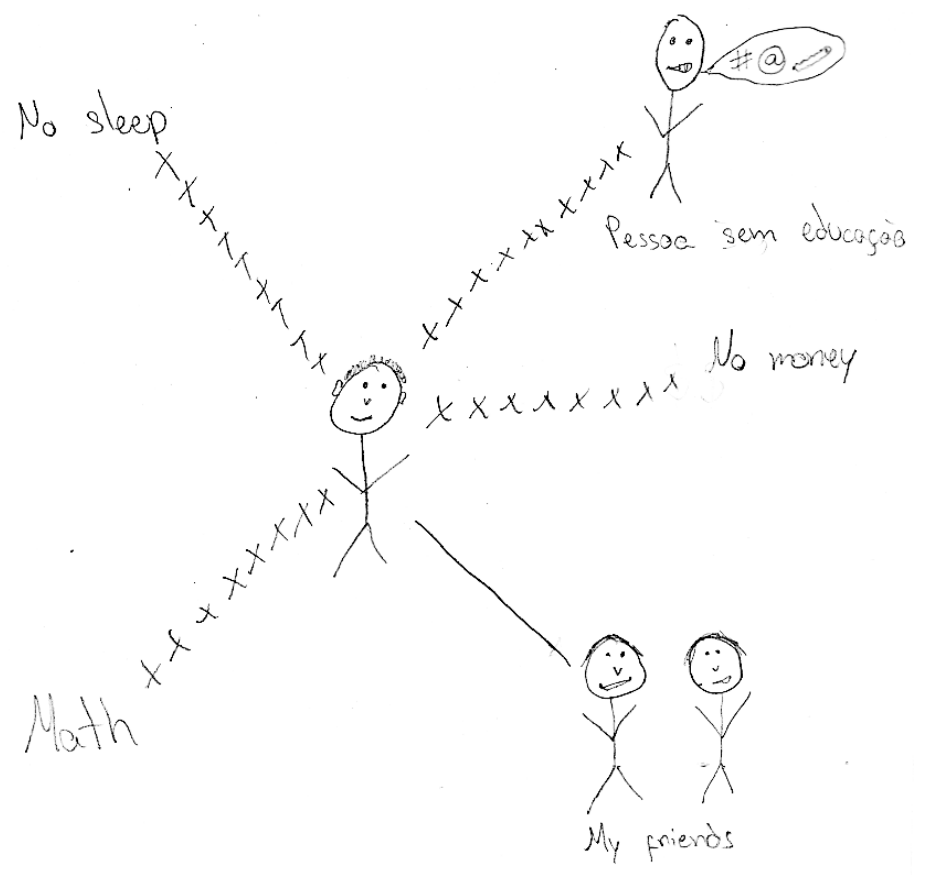

Figure 3. Example of Ecomap: Participant B 


\section{Discussion}

\subsection{Sources of Support and Stress}

Overall, participants identified more sources of support than sources of stress or ambivalent sources. This is an important finding because these supports can bolster the resiliency of this population. Immigrant adolescents in this study most often felt that physical activity (such as exercising or playing sports), their family, and their friends provided them with support, which could help them cope with environmental stressors (Resnick, 2000), such as immigrant status, learning a new language, adapting to a new culture, and a lack of family financial resources. It suggests that despite living in a new country, they have retained a strong sense of connection to other people and to activities that provide them with support.

\subsubsection{Activities}

Exercise and playing sports were the most frequently reported sources of support for this population. This finding suggests that a strong relationship between physical activity and mental health might exist for this immigrant group. Watching and playing soccer, following soccer teams and exercising were frequently identified as a source of support in their Ecomaps and as a coping strategy in the open-ended questionnaire when participants were asked how they cope with stress. In comparison with the perceptions of Chinese immigrant adolescents and Brazilian non-immigrant adolescents, the use of exercise and playing sports appear to be more important for this group of Brazilian immigrant adolescents.

Approximately one-third of the participants also described quantity of homework and specific academic subjects (e.g. mathematics) as stressful. This finding is similar with Lizardi and Carregari's (2016) study with adolescents in Brazil and Li and Li's (2016) study with Chinese immigrant adolescents in the United States. However, unlike Chinese immigrants studied by $\mathrm{Li}$ and $\mathrm{Li}$ (2016) who identified school performance or competition in school as a source of stress, Brazilian immigrant adolescents described the quantity and difficulty of schoolwork as stressful. It is important to note that stressors may be different for immigrants from different cultural backgrounds, even within the same setting, such as school. This is important to note when helping Brazilian adolescents transition to higher education settings. As many of these adolescents may become first generation college students, it is important that bridging programs note that this population may need additional academic support to help them transition from high school to college (Checkoway, 2018).

\subsubsection{People}

Brazilian immigrant adolescents most frequently identified relationships with different family members such as parents, aunts and uncles, siblings, cousins, and grandparents as sources of support in their lives. Half of the participants in the study also identified specific family members as both a source of support and stress in their lives. These results are similar to Li \& Li's (2016) results from a study of Chinese immigrant adolescents, who also identified relationships with parents as ambivalent. Although Lizardi and Carregari's (2016) study of Brazilian adolescents living in Brazil found that adolescents perceived family members as supportive, they did not include a measure of ambivalent relationships in their study. Given that few studies have explored the ambivalence that adolescents feel towards relationships with family members, it is inconclusive whether this ambivalence is heightened by an adolescent's experience with immigration or if it is a reflection of more universal aspects of adolescent development.

Although Brazilian immigrant adolescents in this study identified home-related stressors, they did not identify the same home-related stressors that were identified by Chinese immigrant students (e.g., family conflict, safety issues, and health problems of family members) ( $\mathrm{Li} \& \mathrm{Li}, 2016$ ). This result underscores the importance of not assuming that all groups of adolescent immigrants experience the same stress. It also highlights the need for culture specific research on immigrant adolescents. Furthermore, it seems that adolescents from the same ethnic group may experience different sources of support and stress in different countries. For example, Lizardi and Carregari (2016) found that taking care of a sibling was a source of stress in Brazilian children living in their native country. In contrast, that potential source of stress was identified by only two of the participants in the current study indicating that roles may shift once families migrate to the United States. These shifts in family roles might occur as a result of adolescents taking on new roles in their new country, such as translating for parents or younger siblings (Burgos et al., 2016).

\subsubsection{Places}

School and work were identified most often as a source of both support and stress for this population. Work related stress identified by the Brazilian immigrant adolescents in the current study was not found among Chinese immigrant adolescents in Li and Li's (2016) study or the Brazilian adolescents in Lizardi and 
Carregari's (2016) study. One possible explanation is that the participants in the current study were older than those in the previous two studies, and thus were more likely to have a paid job outside of the home. Another explanation is that compared to immigrants of other ethnic backgrounds, Brazilian immigrant adolescents are more likely to be in the civilian labor force (Zong \& Batalova, 2016). Brazilian immigrant adults value working hard and then returning to Brazil to enjoy their lives (Joseph, 2011). Given that families carry these cultural values as immigrants, Brazilian immigrant adolescents may also feel the pressure to earn money in addition to carrying out their educational responsibilities. It was interesting that only $16 \%$ of participants identified money as a source of stress in their Ecomaps. It is possible that this population feels the pressure to earn money, but their jobs may provide them with sufficient financial stability.

Thirty-two percent participants in the current study identified church as a source of support with an additional 6\% of participants specifically mentioning God as a source of support. The majority of participants did not mention their religious affiliation as a source in their ecomaps. However, consistent with Braga's (2012) study of immigrant youth, $94 \%$ of participants in the current study described being affiliated with a specific religion in their questionnaires. The results of the current study highlight the distinction between religious affiliation and viewing religion as a source of support. Although almost all participants reported being religiously affiliated, it was not one of the most frequently reported sources of support for participants.

\subsection{How Do Participants Cope with Stress?}

Participants also identified activities they do when they are experiencing stress in their responses to the open-ended questionnaire. The majority of participants described listening to music, exercising (e.g., playing soccer, going to the gym), going to sleep, or spending time alone as strategies for coping with stress. A positive relationship has been found between exercise and psychological well-being while a negative relationship between exercise and level of stress that people experience (Scully, Kremer, Meade, Graham \& Dudgeon, 1998). Although 69\% of participants mentioned exercise and playing sports as a source of support in their Ecomaps, only $15 \%$ of participants described exercise or sports as an activity to do when they are experiencing stress. It is possible that although Brazilian adolescent immigrants find sports and exercise to be supportive, they may not understand that physical activity can also be used to reduce stress. Even though sports and exercise appear to be important in supporting Brazilian immigrant adolescents, education related to how physical activity biologically relieves stress may be beneficial to students who find it supportive but do not use it as a way to cope with stress.

Brazilian adolescents living in their native country described responding to stressful events by using strategies (i.e., listening to music and sleeping) (Lizardi \& Carregari, 2016) similar to those used by the group in the present study. However, Lizardi \& Carregari (2016) found that many Brazilians adolescents also described using physically and verbally aggressive actions as ways to cope with stress. These were not evident in the current study of immigrant adolescents. A possible explanation for this discrepancy between the two studies is that the stressors experienced by the population in the current study were less severe than those experienced by adolescents in Brazil. The stressors in the Lizardi and Carregari (2016) study included the death of a loved one or physically or emotionally being hurt by someone. These severe stressors may have been reflective of the more dangerous environment that the population was living in the city of Manaus. In general, the immigrant adolescents in the current study reported using a wider range of positive strategies compared to adolescents living in Brazil.

\subsection{Using Ecomaps to Assess Supports and Stressors for Immigrant Adolescents}

One of the advantages of using the Ecomap is that it allows an individual to identify the ambivalent relationships in a relatively simple map. This tool is especially useful for bilingual populations because they are given the opportunity to write in their preferred language or a combination of both languages to label and/or explain the elements in their pictures. Ecomap is much less demanding of English language skills than an interview because English language learners can write single words or use pictures to tell a story or illustrate what they want to convey. The current study used Ecomaps as an application of the ecological model in order to help identify issues in one's environment and address them. It can be used in the same way in schools or mental health settings to better understand the sources of stress and support in an individual's life.

\subsection{Implications for Promoting Psychological and Academic Wellbeing of Brazilian Immigrant Adolescents}

The current study found that the experiences of Brazilian immigrant adolescents may be unique to their cultural background and life experiences as immigrants, building a case for taking what they find supportive into consideration when designing programs to promote psychological and academic wellbeing for this population. Whereas they shared some experiences (e.g., feeling supported by family members and peers) with other immigrants and Brazilians living in Brazil, they also described supports (e.g., playing sports and exercising) and 
stressors (e.g., quantity and difficulty level of schoolwork, and job-related stressors) that appear to be unique to their experiences as Brazilian adolescents in the United States. Male participants had a pronounced preference for watching and playing soccer as a source of support, possibly because of its primacy in male Brazilian culture. Opportunities for male students to play soccer in school and their communities would be beneficial in reducing their stress levels. Furthermore, soccer related themes in academic content could make school-related tasks more attractive to Brazilian males. This may also be important to note for educators helping Brazilian adolescents transition from high school to college settings. As suggested by Checkoway (2018), when helping first generation college students transition from high school to college, it can be beneficial to allow students to have an opportunity to take courses that incorporate content from their cultural background.

Group results often obscure individual differences. Although cultural differences are important, it is even more crucial to assess an individual's preferences in order to provide appropriate support to a student. Each student's individual cluster of support and stressors is important to consider in enhancing students' psychological and academic wellbeing. The Ecomap examples of Participants A and B highlight the importance of understanding the unique cluster of sources of support and stress for an individual when considering how to best support them. For instance, Participant A, who identified only sources of support, could be a valuable source of support to other immigrant students in the school who are struggling to adjust to their new country. School counselors, psychologists, and social workers should be aware of Participant B's interpersonal issues along with his desire to help others in order to support this student in his new environment. His parents should be aware of his sleep problem identified in the ecomap in order to help him manage his time better and get more sleep. These two examples illustrate that although there are similarities among participants, it is crucial for psychologists and educators to examine the specific cluster of an individual's sources of support and stress to understand the resources and challenges in that person's environment.

\subsection{Limitations of the Study and Directions for Future Research}

The sample in this study is from only one urban high school, which potentially limits the generalizability of the findings to different adolescent groups and geographic locations. Future studies should use samples of different age groups and from different communities. Perceived sources of stress and support may vary by acculturation level of the participants. The current study did not measure participants' acculturation level. To understand the impact of acculturation on Brazilian immigrant adolescents' perceptions of sources of stress and support, future studies should examine the relationship between acculturation levels and perceptions of the sources of stress and support. Because the current study focused on environmental factors, future research should also investigate internal stressors and resilience factors in this population.

It would also be important to gain a deeper understanding of why these sources of support are helpful to this population. It is unknown what internal and external factors contributed to these individuals' perceptions. Ambivalent relationships were not measured on a continuum of how stressful or supportive these were to participants. Therefore, the relative degree of stress and support in these ambivalent relationships is unknown. Thus, it is possible that some ambivalent relationships might have been highly skewed toward either support or stress. Future research should include a measure of the relative strength of the stress and support experienced from these relationships.

\section{Conclusion}

Despite the limitations, the current study provides a unique contribution to the research on what Brazilian adolescent immigrants perceive as stressful, how they cope with stress, and how they help others cope with stress. The participants identified more supports than stressors in their lives, which may be important when they cope with challenges associated with immigration, such as documentation status and language proficiency. Brazilian immigrant adolescents identified culture-specific sources of support that differed from Chinese immigrants and Brazilian adolescents living in Brazil. Playing sports and exercising were among the most frequently identified sources of support, with soccer being identified by 57 percent of male participants as a source of support and as a method to cope with stress. The sources of stress in the lives of these adolescents, such as managing school and work responsibilities, appear to differ from those of Chinese-immigrant adolescents and Brazilian adolescents living in Brazil, indicating that the perceptions of Brazilian immigrant adolescents may be a function of their specific experiences as immigrants. Interventions involving family, friends, and community partnerships (e.g., sports teams) might be particularly beneficial for this population when they migrate to a new country. These findings should be helpful to educators, psychologists, and counselors who want to provide culturally sensitive prevention activities and interventions for this population during their high school years or during their transition to higher education programs. 


\section{References}

Borja, A. P., Nastasi, B. K., \& Sarkar, S. (2017). Children's voices about the functions of their social supports: multicountry perspectives. International Journal of School \& Educational Psychology, 5(3), 152-166. https://doi.org/10.1080/21683603.2016.1276813

Braga, L. J. (2012). From identity to policy: delineating the contexts of acculturation and educational prospects of Brazilian immigrant adolescents in Massachusetts (Doctoral dissertation). Available from ProQuest Dissertations \& Theses: Full Text (UMI No. 3535048).

Bronfenbrenner, U. (1979). Contexts of child rearing: Problems and prospects. American Psychologist, 34(10), 844-850. http://dx.doi.org/10.1037/0003-066X.34.10.844

Burgos, M., Al-Adeimi, M., \& Brown, J. (2017). Protective factors of family life for immigrant youth. Child \& Adolescent Social Work Journal, 34(3), 235-245. http://dx.doi.org/10.1007/s10560-016-0462-4

Checkoway, B. (2018). Inside the gates: first generation students find their way. Higher Education Studies, 8(3), 72-84. https://doi.org/10.5539/hes.v8n3p72

Cicognani, E. (2011). Coping strategies with minor stressors in adolescence: Relationships with social support, self- efficacy, and psychological well-being. Journal of Applied Social Psychology, 41(3), 559-578. http://dx.doi.org/10.1111/j.1559-1816.2011.00726.x

Driessnack, M. (2005). Children's drawings as facilitators of communication: A meta- analysis. Journal of Pediatric Nursing, 20, 415-423. https://doi.org/10.1016/j.pedn.2005.03.011

Hartman, A. (1995). Diagrammatic assessment of family relationships. Families in Society: The Journal of Contemporary Human Services, 76(2), 111-122.

Hodge, D. R., \& Limb, G. E. (2011). Spiritual assessment and Native Americans: Establishing the social validity of a complementary set of assessment tools. Social Work, 56, 213-223.

Joseph, T. D. (2011). "My life was filled with constant anxiety": anti-immigrant discrimination, undocumented status, and their mental health implications for Brazilian immigrants. Race and Social Problems, 3, $170-181$. http://dx.doi.org/10.1007/s12552-011-9054-2

Li, C., \& Li, H. (2016). Longing for a balanced life: Voices of Chinese-American/immigrant adolescents. In Nastasi B., Borja, A. (eds), International handbook of psychological well-being of children and Adolescents. New York, NY: Springer. https://doi.org/10.1007/978-1-4939-2833-0_15

Li, C., \& Vazquez-Nuttall, E. (2009). School consultants as agents of social justice for multicultural children and families. In special issue, Journal of Educational and Psychological Consultation, 19 (1), 26-44. Li, C., \& Vazquez- Nuttall, E. (2009). School consultants as agents of social justice for multicultural children and families. In special issue, Journal of Educational and Psychological Consultation, 19(1), $26-44$. https://doi.org/10.1080/10474410802462769

Lizardi, P. S., \& Carregari, J. C. (2016). Psychological well-being in children and adolescents in Manaus, Amazonas, Brazil. In Nastasi B., Borja, A. (eds), International handbook of psychological well-being of children and Adolescents. New York, NY: Springer. https://doi.org/10.1007/978-1-4939-2833-0_15

Margolis, M. L. (2013). Goodbye, Brazil: Émigrés from the Land of Soccer and Samba. Madison, WI: University of Wisconsin Press. https://doi.org/10.1080/2325548X.2014.954203

Masten, A. S (2003). Commentary: Developmental psychopathology as unifying context for mental health and education models, research, and practice in schools. School Psychology Review, 32, 169-173. Retrieved on October $27^{\text {th }}, 2018$ from www.nasponline.org.

McCormick, K. M., Stricklin, S., Nowak, T. M., \& Rous, B. (2008). Using eco-mapping to understand family strengths and resources. Young Exceptional Children, 11(2), 17-28. https://doi.org/10.1177\%2F1096250607311932

Mesquita, G., \& Reimao, R. (2010). Stress and sleep quality in high school Brazilian adolescents. Anais da Academia Brasileira de Ciencias, 82(2), 545-551.

Morato, M. P., Giglio, S. S., \& Gomes, M. S. P. (2011). The construction of the idol in the football phenomenon. Montriz: The Journal of Physical Education, 17(1), 1-10. http://dx.doi.org/10.5016/19806574.2011v17n1p1

Nastasi, B. K., \& Borja, A. P. (2016). Promoting psychological well-being globally project: Approach to data collection and analysis. In Nastasi B., Borja, A. (eds), International handbook of psychological well-being 
of children and Adolescents. New York, NY: Springer. https://doi.org/10.1007/978-1-4939-2833-0_15

Nastasi, B. K., \& Schensul, S. L. (2005). Contribution of qualitative research to the validity of intervention research. Journal of School Psychology, 43, 177-195. http://dx.doi.org/10.1016/j.jsp.2005.04.003

Nastasi, B. K., Borja, A. P., \& Summerville, M. (2017). Evolution of a mixed methods research tool: Children's social ecologies in their own words. International Journal of Multiple Research Approaches, 10(1), 422-436. https://doi.org/10.29034/ijmra.v10n1a29

Newman, R. (2005). APA's resilience initiative. Professional Psychology: Research and Practice, 36(3), 227-229. http://dx.doi.org/10.1037/0735-7028.36.3.227

Resnick, M. D. (2000). Resilience and protective factors in the lives of adolescents. Journal of Adolescent Health, 27, 1-2. https://doi.org/10.1016/S1054-139X(00)00142-7

Scully, D., Kremer, J., Meade, M., Graham, R., \& Dugeon, K. (1998). Physical exercise and psychological well-being: a critical review. British Journal of Sports Medicine, 32, 111-120.

Summerville, M. (2014). The ecomap as a measure of psychological well-being: results from primary school children identified as at-risk for psychological distress (Unpublished master's thesis). Tulane University, United States of America.

U.S. Census Bureau. (2014). State \& county Quick Facts: Framingham, MA. Retrieved from http://www.census.gov/quickfacts/table/PST045215/2524960

Wiese, E. B. P. (2010). Culture and migration: psychological trauma in children and adolescents. Traumatology, 16(4), 142-152. https://doi.org/10.1177/1534765610388304

Zinn-Sousa, L. C., Nagai, R., Teixeira, L. R., Latorre, M. R. D. O., Roberts, R., Cooper, S. P., \& Fisher, F. M. (2008). Factors associated with depression symptoms in high school students in Sao Paulo, Brazil. Revista de Saude Publica, 42(1), 34-40. http://dx.doi.org/10.1590/S0034-89102008000100005

Zong, J., \& Batalova, J. (2016). Brazilian immigrants in the United States. The Online Journal of the Migration Policy Institute. Retrieved from http://www.migrationpolicy.org/article/brazilian-immigrants-united- states

Zubaran, C. (2008). The quest for recognition; Brazilian immigrants in the United States. Transcultural Psychiatry, 45(4), 590-610. https://doi.org/10.1177/1363461508100784 
Appendix A: Coding Framework

\begin{tabular}{lll}
\hline Theme & \multicolumn{1}{c}{ Sub-theme } & \multicolumn{1}{c}{ Examples of Responses } \\
\hline People & Family Members & Parent; Sibling; Uncle/Aunt; Cousin \\
& Significant Others & Boyfriend; Girlfriend \\
& Friends & Friend; Best friend \\
& School Personnel & Teacher; Guidance Counselor; Principal; Vice Principal \\
& Coworkers & Coworkers \\
Paith & God & God \\
& School & School \\
& Work & Work \\
& Home & Home \\
Religious Places & Church \\
Mall & Mall \\
Different Country & Brazil; Italy \\
Beach & Beach \\
Speaking Languages & Speaking two languages; Learning English \\
Schoolwork & Math; School Projects; Homework \\
Caring for family & Caring for sibling \\
Driving & Driving \\
Skateboarding & Skateboarding \\
Party & Party \\
Eating & Eating; Eating food \\
Time Alone & Walk alone; Time alone \\
Soccer & Playing and watching soccer; Supporting a soccer team \\
Listening to Music & Music; Listening to music \\
Exercise & Playing sports; Exercising; Gym; Wrestling; Basketball \\
Sleep & Sleeping; Sleep \\
Vacation & Vacation; Going on vacation \\
Sing/Dance/Instruments & Capoeira; Dancing; Singing; Piano; Playing guitar \\
Art & Art \\
Shopping & Shopping \\
Video Games & Playing videogames \\
TV & Watching TV \\
Hangout/Go out & Hang out with friends; Going out; Hanging out \\
College Applications & College Applications \\
Food & Food; Chocolate \\
Money & Money; Bills \\
Pet & Pet; Cat; Dog \\
Motorcycle & Motorcycle \\
Books & Books \\
Society & Society \\
Legal Status & Legal Status; Legal Documentation \\
\hline
\end{tabular}

\section{Copyrights}

Copyright for this article is retained by the author(s), with first publication rights granted to the journal.

This is an open-access article distributed under the terms and conditions of the Creative Commons Attribution license (http://creativecommons.org/licenses/by/4.0/). 